\title{
Caracterização físico-química de creme vegetal enriquecido com ésteres de fitosteróis
}

\author{
Juliana Neves Rodrigues', Jorge Mancini Filho², Rosângela Pavan Torres², Luiz Antonio Gioielli* \\ ${ }^{1}$ Departamento de Tecnologia Bioquímico-Farmacêutica, ${ }^{2}$ Departamento de Alimentos e Nutrição Experimental, \\ Faculdade de Ciências Farmacêuticas, Universidade de São Paulo
}

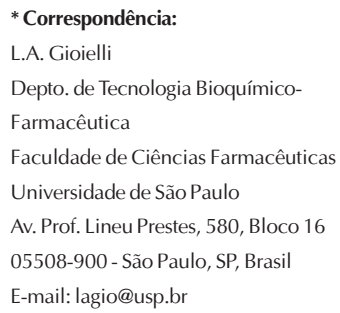

Atualmente, esteróis e estanóis têm sido adicionados a margarinas especiais, comercialmente disponiveis como alimentos funcionais, com o intuito de reduzir os níveis de colesterol. Como parte de uma dieta saudável, é cientificamente comprovado que esse tipo de produto reduz o colesterol LDL em aproximadamente 10-15\%. A literatura disponivel sobre os efeitos dos fitosteróis/fitostanóis na redução do colesterol no organismo, bem como a forma como estes componentes são metabolizados, é muito vasta. Porém, informações sobre as propriedades físicas e químicas destas substâncias e os efeitos de sua aplicação em alimentos, do ponto de vista tecnológico, dificilmente são encontradas. Este trabalho tem como objetivo caracterizar um creme vegetal enriquecido com fitosteróis e comparar suas propriedades físicas com as de margarinas comuns disponiveis comercialmente. As composições em ácidos graxos e em esteróis foram determinadas por cromatografia gasosa. Foram, também, analisados ponto de amolecimento, textura, composição química e estrutura cristalina. O creme vegetal enriquecido é composto de 49,3\% de umidade, 49,6\% de lipídios e 1,1\% de sólidos. $O \beta$-sitosterol é o esterol mais abundante, constituindo $36,1 \%$ do total de esteróis. O ácido linoléico (C18:2 n-6) corresponde a 45,3\% do total de ácidos graxos e é o que está presente em maior quantidade. Em geral, as propriedades de textura da base gordurosa e do creme vegetal apresentaram correlação linear significativa. Embora um pouco mais duro que as margarinas cremosas comerciais, o creme vegetal com fitosteróis apresenta plasticidade satisfatória na faixa de temperatura entre a de refrigeração e a ambiente e maior resistência à temperatura do que as margarinas cremosas. Em geral, os ésteres de fitosteróis apresentaram comportamento de fusão e cristalização diferentes dos óleos e gorduras comestiveis.
Unitermos

- Margarina

- Creme vegetal

- Ésteres de fitosteróis

- Cristalização 


\section{INTRODUÇÃO}

A margarina foi inicialmente desenvolvida em 1869, como um substituto da manteiga, pelo químico francês Hippolyte Mege Mouries (Hui, 1996). Atualmente, entretanto, é um produto de alta tecnologia, com características próprias e muitas variações (Gioielli, 1996a).

Segundo a legislação brasileira, de acordo com a Portaria 372 da DIPOA, entende-se por margarina o produto gorduroso em emulsão estável com leite ou seus constituintes ou derivados, e outros ingredientes, destinado à alimentação humana com cheiro e sabor característicos. A gordura láctea, quando presente, não deverá exceder a 3\% $(\mathrm{m} / \mathrm{m})$ do teor de lipídios totais (Brasil, 1997). O creme vegetal é comercializado juntamente com a margarina, porém o consumidor não tem consciência de que há diferença entre os dois produtos. De acordo com a Portaria 193 da ANVISA, creme vegetal é o alimento em forma de emulsão plástica, cremoso ou líquido, do tipo água/óleo, produzido a partir de óleos e/ou gorduras vegetais comestíveis, água e outros ingredientes, contendo, no máximo, 95\% (m/m) e, no mínimo, $10 \%(\mathrm{~m} / \mathrm{m})$ de lipídios totais (Brasil, 1999).

O mercado brasileiro de margarinas e cremes vegetais é de cerca de 400 mil toneladas/ano, ou R $\$ 1$ bilhão em faturamento (Dantas, 2000).

Atualmente, a atenção dos pesquisadores está voltada ao desenvolvimento de alimentos funcionais, que promovam o bem-estar e a saúde, ao mesmo tempo em que reduzem os riscos de algumas doenças (Roberfroid, 1999). A Comissão Tecnocientífica de Assessoramento em Alimentos Funcionais e Novos Alimentos, órgão do Ministério da Saúde, definiu alimentos funcionais como aqueles semelhantes em aparência ao alimento convencional, consumidos como parte da dieta usual, capazes de produzir demonstrados efeitos metabólicos ou fisiológicos úteis na manutenção de uma boa saúde física e mental, podendo auxiliar na redução do perigo de doenças crônicodegenerativas, além das suas funções nutricionais básicas (Lajolo, 1999). Mais importante, entretanto, é o potencial dos alimentos funcionais em diminuir as doenças, promover a saúde e reduzir os custos com os cuidados com a saúde. $\mathrm{O}$ mercado dos chamados alimentos funcionais triplicou nos últimos dois anos, refletindo a preocupação crescente do consumidor com a relação entre alimentação e doenças. Em 2001, os consumidores brasileiros gastaram quase US\$ 950 milhões em tais alimentos (Winnett, 2002).

Recentemente, fitosteróis e fitostanóis têm sido adicionados a margarinas especiais, que estão comercialmente disponíveis como alimentos funcionais com capacidade de reduzir os níveis de colesterol total e LDL. Foi prova- do que seu consumo como parte de uma dieta saudável implica diminuição no risco de doenças cardíacas em $25 \%$. Esta combinação pode até evitar a necessidade de medicamentos para indivíduos com níveis moderadamente altos de colesterol (Ntanios, 2001; Weber, Weitkamp, Mukherjee, 2002).

Nos Estados Unidos, estes produtos são encontrados desde 1999, dos quais os mais conhecidos são as margarinas Benecol e Take Control. As dificuldades iniciais em formular margarinas ou "spreads" com fitosteróis eram decorrentes da insolubilidade desses componentes. A esterificação dos mesmos tornou-os mais solúveis e facilitou a inclusão nas formulações de quantidades suficientes em produtos comestíveis para serem efetivas no combate ao colesterol. Quando esterificados, os componentes podem ser solubilizados prontamente em óleos vegetais, de forma que uma quantidade adequada de fitosteróis fique disponível, sem causar problemas com a solubilidade das vitaminas (Turatti, 2001; Nestel et al., 2001).

Em geral, óleos vegetais e produtos derivados de óleos são considerados as fontes naturais mais ricas em esteróis, seguidos pelos cereais, produtos a base de cereais e castanhas (Piironen et al., 2000).

No organismo, os fitosteróis, dos quais os mais comuns são o campesterol, o sitosterol e o estigmasterol, atuam na diminuição da absorção de colesterol no intestino delgado por um mecanismo de competição, com conseqüente aumento na excreção fecal. Esta competição ocorre porque a estrutura química dos fitosteróis é semelhante à do colesterol, diferindo no tamanho da cadeia. Entretanto, os mecanismos exatos que levam à redução substancial na absorção de colesterol de cerca de $50 \%$ ainda não foram totalmente compreendidos (Hornstra, 1999; Dillard, German, 2000; Piironen et al., 2000; Nestel et al., 2001; Ntanios, 2001).

O mercado tem se mostrado aberto à introdução de outros tipos de alimentos, que contêm fitosteróis, além das margarinas. O mercado mundial de esteróis para produção de margarinas e similares tem demanda de 50 ton/ano (Turatti, 2001). Já existem pesquisas sobre a adição de fitosteróis em iogurtes (Volpe et al., 2001).

A literatura disponível sobre os efeitos dos fitosteróis na redução do colesterol no organismo humano, bem como a forma como estes componentes são metabolizados, é muito vasta. Porém, informações sobre as propriedades físicas e químicas destas substâncias e os efeitos de sua aplicação em alimentos, do ponto de vista tecnológico, dificilmente são encontradas. Este trabalho teve como objetivo avaliar as características físicas e químicas de creme vegetal contendo ésteres de fitosteróis, comparando-o com margarinas comuns disponíveis no mercado brasileiro. 


\section{MATERIAL E MÉTODOS}

\section{Matéria-prima}

Este estudo foi feito a partir das seguintes matériasprimas:

a) creme vegetal com fitosteróis ( $14 \%$ de ésteres de fitosteróis);

b) gordura do creme vegetal com fitosteróis;

c) ésteres de fitosteróis.

O creme vegetal com fitosteróis foi adquirido no varejo. A gordura do produto foi obtida por fusão completa à temperatura de $70{ }^{\circ} \mathrm{C}$, em estufa, para quebrar a emulsão, separando a fase gordurosa da aquosa. A maior parte da fase aquosa foi separada por decantação. A fase gordurosa, que se apresentava turva devido à presença de umidade, foi filtrada em papel de filtro, processo também realizado em estufa a $70^{\circ} \mathrm{C}$, para retirada da fase aquosa restante.

Os ésteres de fitosteróis (L\&P Food Ingredient Co., Ltd., Guangdong Food Industry Institute) foram doados pela empresa Tovani Benzaquen Representações Ltda.

\section{Teor de umidade}

O teor de umidade do creme vegetal com fitosteróis foi determinado por secagem até peso constante em estufa a $105^{\circ} \mathrm{C}$. Amostras de $10 \mathrm{~g}$ foram pesadas em balança analítica e colocadas sobre $30 \mathrm{~g}$ de areia lavada em cápsulas de porcelana. A determinação foi feita em triplicata (Pregnolatto, 1985).

\section{Teor de gordura}

A extração da gordura do creme vegetal com fitosteróis foi realizada pelo método de Soxhlet, com éter etílico. A determinação foi feita em triplicata (Pregnolatto, 1985).

\section{Teor de sólidos}

O teor de sólidos do creme vegetal com fitosteróis foi determinado a partir da fase aquosa do produto, separada da fase gordurosa após fusão. A fase aquosa foi submetida a secagem até peso constante em cápsula de porcelana, em estufa a $105^{\circ} \mathrm{C}$ (Pregnolatto, 1985).

\section{Composição em esteróis}

As composições em esteróis da gordura do creme vegetal com fitosteróis e dos ésteres de fitosteróis foram determinadas por cromatografia em fase gasosa, segundo Naeemi et al. (1995) em cromatógrafo a gás GC 17 A Shimadzu/Class GC 10. Foi utilizada coluna cromatográfica de sílica fundida J\&W DB-5 com $30 \mathrm{~m}$ de comprimento e $0,25 \mathrm{~mm}$ de diâmetro interno. As condições foram: razão de divisão da amostra no injetor 50:1; temperatura da coluna, $180^{\circ} \mathrm{C}$, programada para aquecimento até $280^{\circ} \mathrm{C}$ a $20^{\circ} \mathrm{C} / \mathrm{min}$, permanecendo nesta temperatura por $10 \mathrm{~min}$; gás de arraste, hélio $(1,5 \mathrm{~mL} / \mathrm{min})$; temperatura do injetor $290{ }^{\circ} \mathrm{C}$; temperatura do detector $300{ }^{\circ} \mathrm{C}$. A composição qualitativa foi determinada por comparação dos tempos de retenção dos picos com os dos respectivos padrões de esteróis, com cromatogramas encontrados em literatura, catálogos e com a composição de esteróis apresentada no certificado de análise fornecido pela empresa fabricante dos ésteres de fitosteróis. A composição quantitativa foi realizada por normalização de área, sendo expressa como porcentagem em massa. As análises foram feitas em triplicata.

\section{Composição em ácidos graxos}

As composições em ácidos graxos do creme vegetal com fitosteróis e dos ésteres de fitosteróis foram determinadas por cromatografia em fase gasosa, segundo normas da American Oil Chemists' Society (1990), método Ce 1-62. Foi empregado cromatógrafo a gás Varian GC, modelo 3400CX, equipado com detector de ionização de chama e "Workstation Star Chromatography". Foi utilizada coluna capilar de sílica fundida CP WAX $52 \mathrm{CB}$ (Chrompack), com 30 metros de comprimento e $0,25 \mathrm{~mm}$ de diâmetro interno, contendo $0,25 \mu \mathrm{m}$ de polietilenoglicol. As condições foram: razão de divisão da amostra no injetor 50:1; temperatura da coluna: $150^{\circ} \mathrm{C}$ por 5 minutos, programada até $215^{\circ} \mathrm{C}$ numa razão de $3{ }^{\circ} \mathrm{C} / \mathrm{min}$; gás de arraste: hélio (1,5 $\mathrm{mL} / \mathrm{min})$; gás make-up: hélio $(30 \mathrm{~mL} / \mathrm{min})$; temperatura do injetor: $250{ }^{\circ} \mathrm{C}$; temperatura do detector: $280^{\circ} \mathrm{C}$. A composição qualitativa foi determinada por comparação dos tempos de retenção dos picos com os dos respectivos padrões de ácidos graxos. A composição quantitativa foi realizada por normalização de área, sendo expressa como porcentagem em massa. Os ésteres metílicos de ácidos graxos para a análise foram obtidos de acordo com o método descrito por Hartman e Lago (1973). As análises foram feitas em duplicata.

\section{Ponto de amolecimento}

O ponto de amolecimento da gordura do creme vegetal e dos ésteres de fitosteróis foi determinado pelo método do tubo capilar aberto, imerso em água sob agita- 
ção e aquecimento, de acordo com o método oficial Cc 325 da American Oil Chemists' Society (1990). As amostras foram analisadas em triplicata.

\section{Textura}

As análises de textura das amostras foram realizadas utilizando o equipamento analisador de textura TAXT2, fabricado pela SMS (Stable Micro Systems), controlado pelo programa Texture Expert. Os cremes vegetais com fitosteróis foram mantidos em suas embalagens plásticas originais $(250 \mathrm{~g})$, armazenados em geladeira comum $\left(5-8{ }^{\circ} \mathrm{C}\right)$ e transferidos para estufa, onde foram mantidas sob temperatura controlada por 24 horas. A gordura do creme vegetal foi aquecida em forno de microondas, até temperatura de $60-70{ }^{\circ} \mathrm{C}$, para fusão completa dos cristais, e acondicionada em béqueres de $100 \mathrm{~mL}$. As amostras foram mantidas por 24 horas em geladeira comum para a recristalização da gordura e posteriormente por 24 horas em estufa a temperatura controlada. Todas as amostras foram analisadas às temperaturas de $5 \mathrm{a} 35^{\circ} \mathrm{C}$, em intervalos de $5{ }^{\circ} \mathrm{C}$. Foi utilizado cone de acrílico com ponta não truncada e ângulo de $45^{\circ}$. Os testes foram operados em triplicata nas seguintes condições:

- Retorno ao início;

- Distância $=10 \mathrm{~mm}$;

- Velocidade $=2 \mathrm{~mm} / \mathrm{s}$;

- Tempo $=5 \mathrm{~s}$;

- Determinação da força em compressão (gf);

- Triplicata: 3 compressões em cada embalagem de creme vegetal e 1 compressão em cada um de três béqueres contendo amostras de gordura do creme vegetal (Rodrigues, Gioielli, Anton, 2003; D’Agostini, Ferraz, Gioielli, 2000).

As amostras foram analisadas quanto à consistência ("yield value"). Para o cálculo do "yield value" foi utilizada a seguinte equação, proposta por Haighton (1959):

$$
C=K \frac{W}{p^{1,6}}
$$

onde:

$\mathrm{C}=$ "yield value" $\left(\mathrm{gf} / \mathrm{cm}^{2}\right)$

$\mathrm{K}=$ fator dependente do ângulo do cone

$\mathrm{W}=$ força em compressão (gf), para tempo de $5 \mathrm{~s}$.

$\mathrm{p}=$ profundidade de penetração $(0,1 \mathrm{~mm})$.

Outras propriedades das amostras podem ser obtidas com o analisador de textura TA-XT2, como firmeza, energia para penetração do cone e adesividade. A firmeza das amostras corresponde à inclinação da curva força- deformação (gf/cm). A energia necessária para a penetração das amostras pelo cone corresponde à área sob a curva força-deformação (gf.cm). A adesividade das amostras ao cone corresponde à área negativa sob a curva força-deformação (gf.cm) (Gioielli, 1996b).

\section{Microscopia sob Luz Polarizada}

Para observação da estrutura cristalina, as amostras foram fundidas a $80^{\circ} \mathrm{C}$, em forno de microondas, e, utilizando-se um tubo capilar, uma gota de amostra foi colocada sobre uma lâmina de vidro pré-aquecida a $60^{\circ} \mathrm{C}$. A gota foi, então, coberta com uma lamínula. As lâminas preparadas foram mantidas em estufa a temperatura controlada por 24 horas e, em seguida, observadas ao microscópio de luz polarizada Olympus BX50. Este é ligado a uma câmera digital (CoolSnap Pro, Media Cybernetics), que transmite as imagens para o computador utilizando o software Image Pro-Plus versão 4.5.1.22 (Media Cybernetics). A partir destas imagens, para cada lâmina foram escolhidos cinco campos (os quatro cantos da lamínula e o centro) e as imagens foram capturadas. Foram preparadas duas lâminas para cada amostra, totalizando dez imagens para serem analisadas. Com o software Image Pro-Plus foram determinados os diâmetros dos cristais e com o software Benoit 1.3 (TruSoft International Inc.) foi determinada a dimensão fractal das amostras, pelo método da contagem de caixas (Simões, Gioielli, 1999, 2000; Sotero-Solis, Gioielli, 2001; Gioielli, Simões, Rodrigues, 2003).

\section{RESULTADOS E DISCUSSÃO}

Segundo informações contidas no rótulo do creme vegetal analisado, o produto contém $40 \%$ de lipídios e $14 \%$ de ésteres de fitosteróis. Os ésteres de fitosteróis são classificados como lipídios complexos e correspondem a mistura de esteróis e ácidos graxos ligados entre si (Nawar, 1985). Segundo a Tabela I, que apresenta a composição centesimal do creme vegetal com fitosteróis, a amostra analisada apresentou $49,6 \%$ de lipídios, aproximadamente $4 \%$ a menos do que a informação contida no rótulo, considerando-se a somatória de lipídios e ésteres de fitosteróis.

A água está presente no produto em $49,3 \%$, o que estabelece relação aproximada de 1:1 entre lipídios e água. O teor de sólidos encontrado nas amostras analisadas confere com o teor de sal, que foi discriminado no rótulo, de $1,1 \%$. O teor de sólidos do creme vegetal pode ser totalmente atribuído ao teor de sal pois, conforme a legislação (Brasil, 1997; 1999), os cremes vegetais não precisam conter leite em sua formulação. 
TABELA I - Composição centesimal do creme vegetal com fitosteróis

\begin{tabular}{lr}
\hline Composição centesimal & $\mathbf{( \% )}$ \\
\hline Umidade & 49,3 \\
Lipídios & 49,6 \\
Sólidos & 1,1 \\
Total & 100,0 \\
\hline
\end{tabular}

A Tabela II apresenta a composição em esteróis da gordura do creme vegetal com fitosteróis e dos ésteres de fitosteróis. Os respectivos perfis cromatográficos estão representados nas Figuras 1 e 2. A composição em esteróis do creme vegetal foi semelhante à dos ésteres de fitosteróis. $O \beta$-sitosterol, o campesterol e o estigmasterol são os esteróis mais abundantes nas duas amostras, assim como na natureza estes são os mais comumente encontrados (Piironen et al., 2000). O $\Delta^{5}$-avenasterol não foi detectado na amostra de creme vegetal.

A Tabela III apresenta as composições em ácidos graxos do creme vegetal com fitosteróis e dos ésteres de fitosteróis e nas Figuras 3 e 4 estão representados seus respectivos perfis cromatográficos.

Comparando a composição do creme vegetal com a do óleo de soja especificada pela legislação brasileira (Brasil, 1999), verificou-se semelhança entre elas, porém com teor de ácido láurico (12:0) do creme vegetal acima do normal para o óleo de soja. A gordura de palmiste é uma

TABELA II - Composição em esteróis da gordura do creme vegetal com fitosteróis e dos ésteres de fitosteróis

\begin{tabular}{lcr}
\hline Esteróis & \multicolumn{2}{c}{ Teor \pm DP (\%) } \\
& $\begin{array}{c}\text { Creme vegetal } \\
\text { com fitosteróis }\end{array}$ & $\begin{array}{c}\text { Ésteres de } \\
\text { fitosteróis }\end{array}$ \\
\hline Colesterol & $0,3 \pm 0,0$ & $0,2 \pm 0,2$ \\
Brassicasterol & $2,3 \pm 0,2$ & $7,0 \pm 2,1$ \\
Campesterol & $21,2 \pm 1,7$ & $18,5 \pm 3,2$ \\
Campestanol & $0,3 \pm 0,0$ & $1,0 \pm 0,6$ \\
Estigmasterol & $14,6 \pm 1,2$ & $11,7 \pm 2,6$ \\
Clerosterol & $1,6 \pm 0,3$ & $2,8 \pm 1,5$ \\
$\beta$-Sitosterol & $36,1 \pm 3,3$ & $26,2 \pm 5,0$ \\
$\beta$-Sitostanol & $1,6 \pm 0,1$ & $2,5 \pm 1,7$ \\
$\Delta^{5}$-Avenasterol & - & $0,1 \pm 0,1$ \\
$\Delta^{5,24}$-Estigmastadienol & $3,6 \pm 1,2$ & $3,9 \pm 2,1$ \\
$\Delta^{7}$-Estigmastenol & $0,9 \pm 0,3$ & $1,6 \pm 1,3$ \\
$\Delta^{7}$-Avenasterol & $2,7 \pm 0,8$ & $2,8 \pm 1,5$ \\
Não identificados & $14,8 \pm 3,6$ & $21,7 \pm 5,5$ \\
\hline
\end{tabular}

fonte rica neste ácido graxo, o que leva a crer que ela também esteja presente na base gordurosa utilizada neste creme vegetal. A partir das composições do óleo de soja e da gordura de palmiste, baseando-se em cálculos de média ponderada aplicados a misturas destes dois componentes, estima-se que a base gordurosa do produto seja mistura de cerca de $85 \%$ óleo de soja com cerca de $15 \%$ de gordura de palmiste. Ressalta-se que a base gordurosa do creme vegetal foi modificada por interesterificação. A preferência pela interesterificação como alternativa à hidrogenação é devida à tendência atual em diminuir a presença de ácidos graxos trans (Gioielli, 2002; Koletzko, Decsi, 1997; Lichtenstein et al., 1999; 2001; 2003; Muller, Kirkhus, Pedersen, 2001; Oliveira et al., 2003; Rodrigues, Gioielli, Anton, 2003; Rousseau et al., 1996; Rousseau, Hill, Marangoni, 1996a,b; Willis, Lencki, Marangoni, 1998).

TABELA III - Composição em ácidos graxos da gordura do creme vegetal com fitosteróis e dos ésteres de fitosteróis

\begin{tabular}{|c|c|c|}
\hline \multirow[t]{2}{*}{ Ácido graxo } & \multicolumn{2}{|c|}{ Teor \pm DP $(\%)$} \\
\hline & $\begin{array}{l}\text { Creme vegetal } \\
\text { com fitosteróis }\end{array}$ & $\begin{array}{l}\text { Ésteres de } \\
\text { fitosteróis }\end{array}$ \\
\hline $6: 0$ & - & $2,9 \pm 0,0$ \\
\hline $8: 0$ & $0,5 \pm 0,0$ & $3,4 \pm 0,1$ \\
\hline $10: 0$ & $0,5 \pm 0,0$ & $0,5 \pm 0,0$ \\
\hline $12: 0$ & $6,2 \pm 0,2$ & $1,5 \pm 0,0$ \\
\hline $14: 0$ & $1,9 \pm 0,0$ & $1,9 \pm 0,0$ \\
\hline $16: 0$ & $12,6 \pm 0,1$ & $6,7 \pm 0,2$ \\
\hline $17: 0$ & - & $0,6 \pm 0,3$ \\
\hline $18: 0$ & $8,8 \pm 0,0$ & $4,0 \pm 0,1$ \\
\hline $18: 1(n-9 c)$ & $18,0 \pm 0,0$ & $20,2 \pm 0,2$ \\
\hline $18: 1(n-9 t)$ & $1,3 \pm 0,2$ & $1,2 \pm 0,0$ \\
\hline $18: 2(n-6)$ & $45,3 \pm 0,0$ & $8,7 \pm 1,8$ \\
\hline $18: 3(n-6)$ & - & $2,9 \pm 0,2$ \\
\hline $18: 3(n-3)$ & $4,9 \pm 0,0$ & $2,6 \pm 0,1$ \\
\hline $18: 4(n-3)$ & - & $4,5 \pm 0,2$ \\
\hline $20: 0$ & - & $0,5 \pm 0,0$ \\
\hline $20: 1$ & - & $2,7 \pm 0,1$ \\
\hline $20: 2$ & - & $3,5 \pm 0,0$ \\
\hline $20: 5(n-3)$ & - & $3,3 \pm 0,1$ \\
\hline $22: 0$ & - & $0,6 \pm 0,0$ \\
\hline $22: 1$ & - & $24,3 \pm 0,6$ \\
\hline $22: 2$ & - & $2,2 \pm 0,0$ \\
\hline $24: 0$ & - & $1,3 \pm 0,0$ \\
\hline Poliinsaturados & 50,2 & 27,7 \\
\hline Monoinsaturados & 19,3 & 48,4 \\
\hline Saturados & 30,5 & 23,9 \\
\hline Total & 100,0 & 100,0 \\
\hline
\end{tabular}




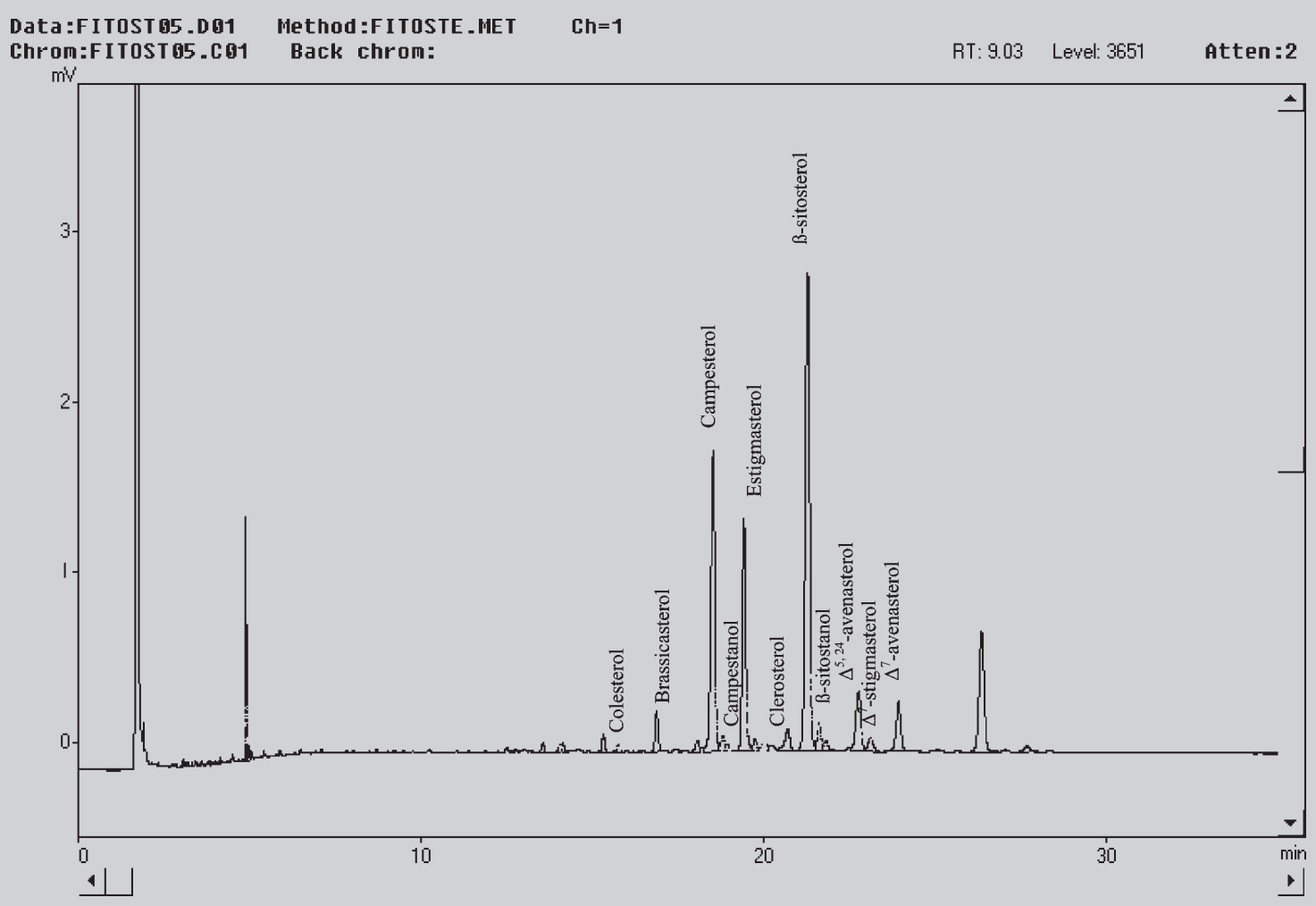

FIGURA 1 - Perfil cromatográfico da composição em esteróis da gordura do creme vegetal com ésteres de fitosteróis.

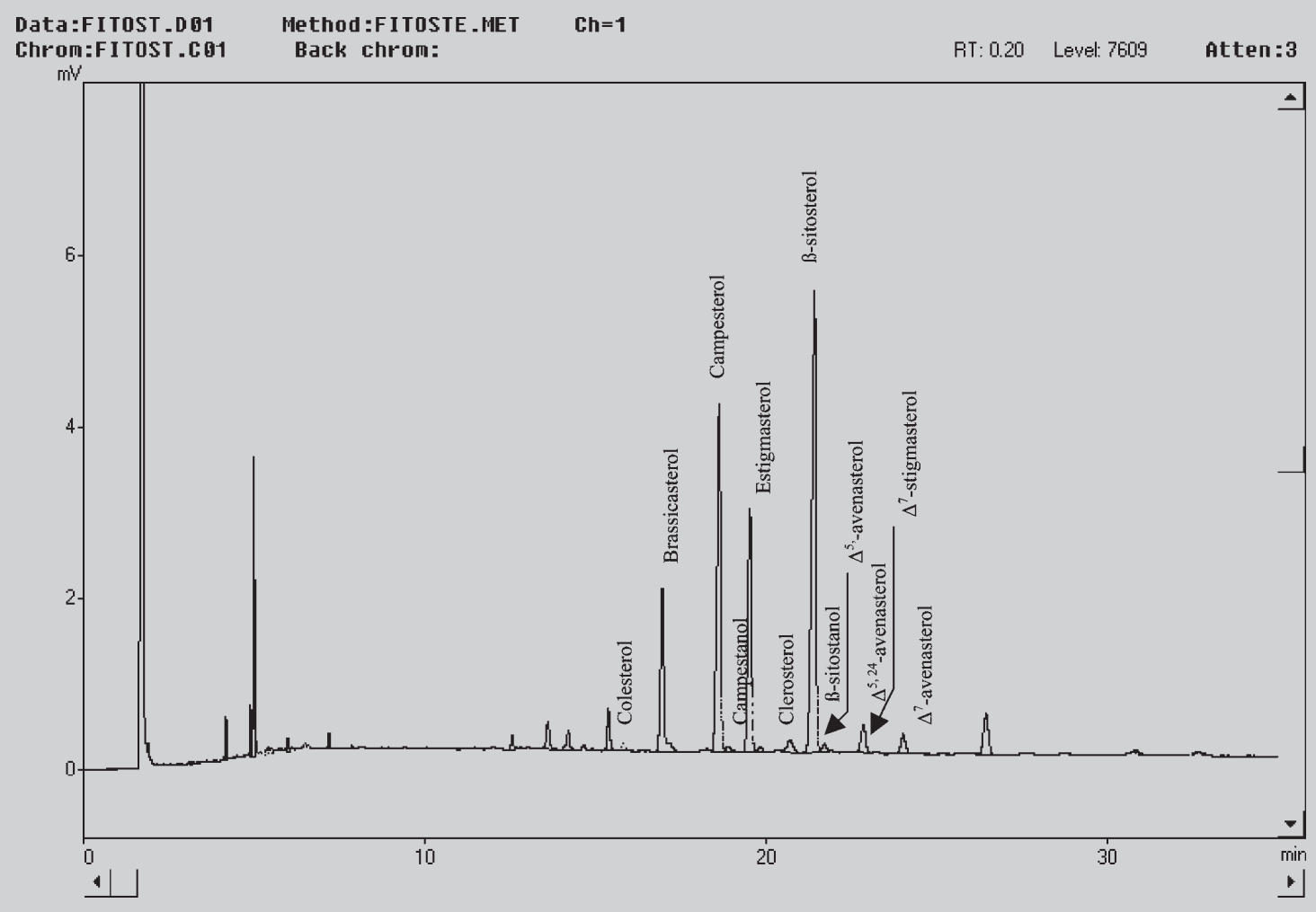

FIGURA 2 - Perfil cromatográfico da composição em esteróis dos ésteres de fitosteróis. 


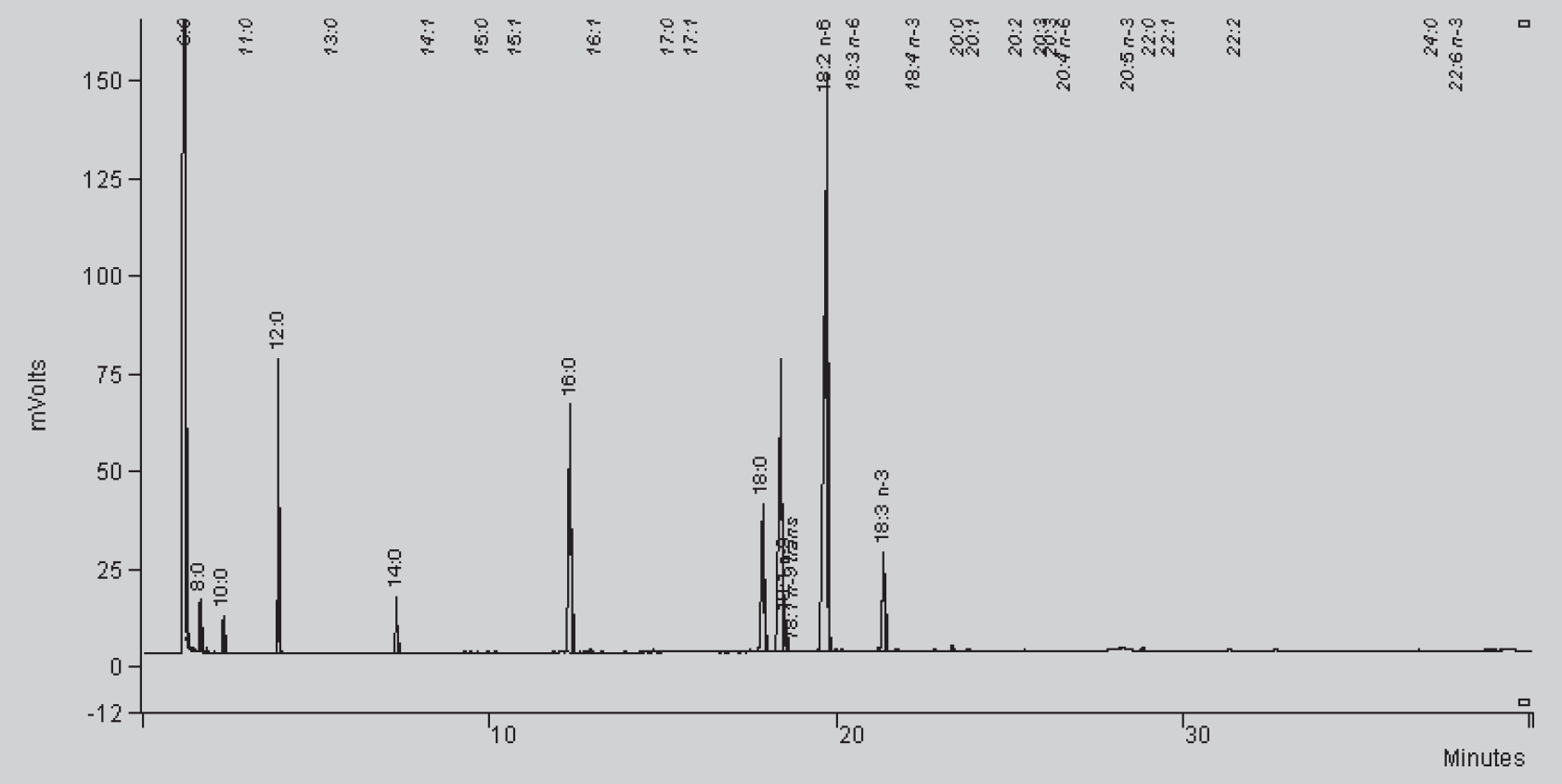

FIGURA 3 - Perfil cromatográfico da composição em ácidos graxos da gordura do creme vegetal com ésteres de fitosteróis.

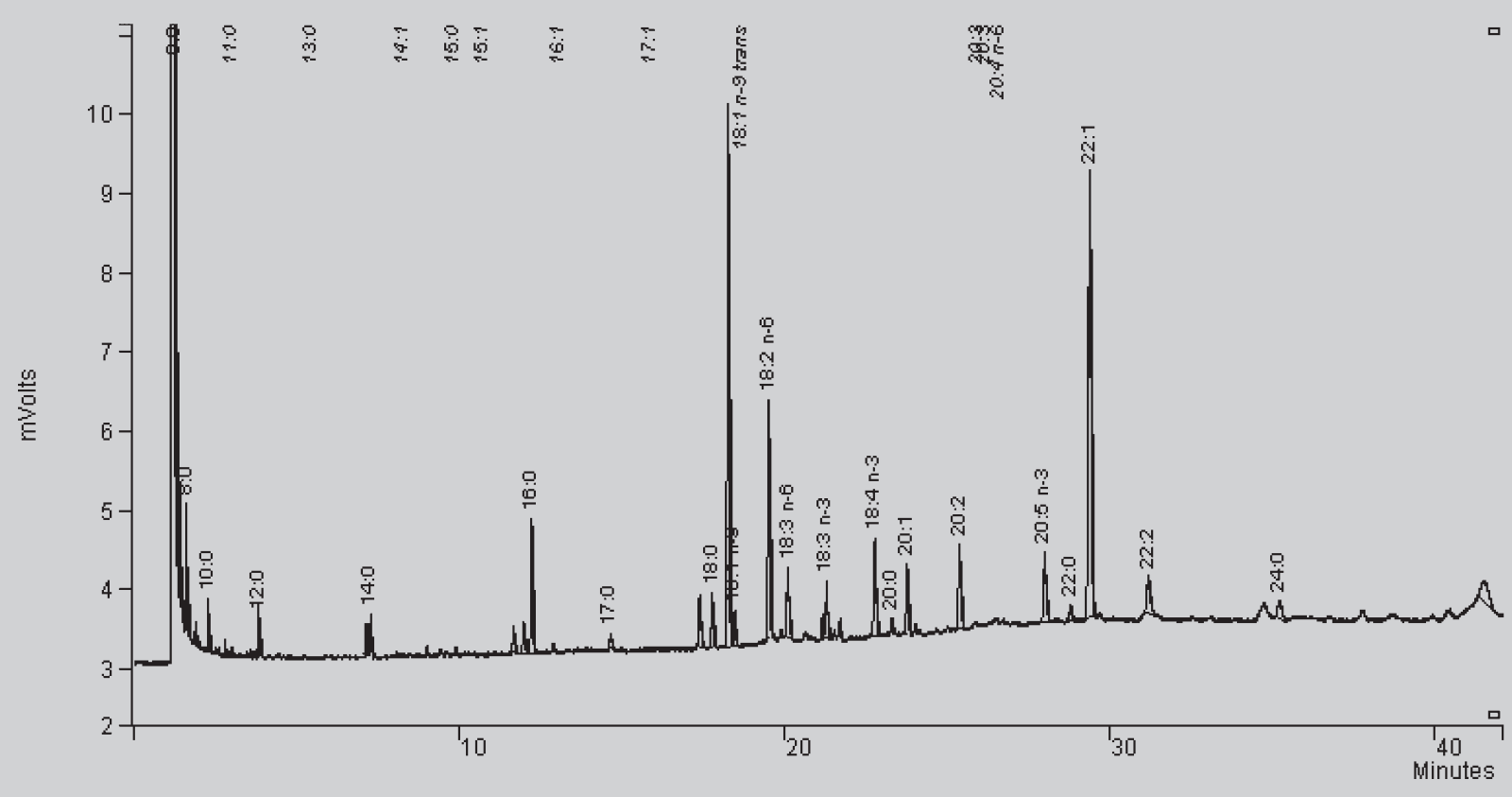

FIGURA 4 - Perfil cromatográfico da composição em ácidos graxos dos ésteres de fitosteróis.

A composição em ácidos graxos dos ésteres de fitosteróis apresenta grande diversidade de ácidos graxos. Segundo a especificação do produto, a matéria-prima da qual foram extraídos os fitosteróis são os óleos de canola e soja. Devido à presença de quase $25 \%$ do ácido erúcico (22:1), de ácidos graxos de cadeia média e de ácido g- linolênico, é provável que os fitosteróis tenham sido obtidos na forma livre e, posteriormente, esterificados com misturas de ácidos graxos livres provenientes de óleo de colza, gordura láurica e óleos como os de prímula, borage ou groselha preta. De acordo com Stauffer (1996), o óleo de colza contém cerca de $40 \%$ de ácido erúcico e é pro- 
duzido em larga escala na China (país de origem do produto), Índia, Europa e Canadá (Lackey, 2003). A esterificação dos esteróis com ácidos graxos visa a aumentar a solubilidade do produto em óleos e gorduras (Turatti, 2001; Nestel et al., 2001).

O ponto de amolecimento de gorduras é utilizado como maneira de determinar os pontos de fusão de diversos produtos alimentícios (Rousseau, Marangoni, 1999). Estes produtos geralmente são constituídos de misturas de óleos e gorduras com o intuito de atingir a propriedade funcional desejada, de maneira que sua gordura não apresenta um ponto de fusão definido. As gorduras passam por um estágio de amolecimento gradual antes de se tornarem totalmente líquidas (AOCS, 1990). O ponto de amolecimento da gordura do creme vegetal com fitosteróis é de $32,5 \pm 0,4{ }^{\circ} \mathrm{C}$ e o dos ésteres de fitosteróis é de $24,3 \pm$ 0,0 ${ }^{\circ} \mathrm{C}$. Gioielli (1996b) determinou os pontos de amolecimento de margarinas comerciais duras e cremosas, duas marcas de cada tipo, que variaram de 34,3 a 36,3 para as duras e de 31,5 a 35,3 para as cremosas. Block \& Barrera-Arellano (1994) verificaram que o ponto de amolecimento de 14 amostras de margarinas brasileiras variou entre 30,6 e 38,6. O creme vegetal com fitosteróis apresentou, portanto, ponto de amolecimento semelhante aos encontrados para margarinas comerciais.
As Tabelas IV, V, VI e VII apresentam as propriedades de textura do creme vegetal com fitosteróis, de sua gordura e dos ésteres de fitosteróis nas temperaturas de 5 a $30{ }^{\circ} \mathrm{C}$. As propriedades de consistência, firmeza e energia necessária para a penetração do cone diminuem com o aumento da temperatura, que provoca a fusão gradual dos cristais e, conseqüentemente, a destruição da rede cristalina, o que confere plasticidade à gordura (Deman, 1983).

A partir dos dados apresentados nas Tabelas IV, V, VI e VII, foi efetuada uma correlação entre os valores experimentais de cada propriedade de textura do creme vegetal com fitosteróis e os de sua base gordurosa às temperaturas de 5 a $15{ }^{\circ} \mathrm{C}$ por regressão linear simples. A equação da reta correspondente é a seguinte:

$$
y=a x+b
$$

onde: $y=$ propriedade do creme vegetal; $x=$ propriedade de sua base gordurosa; $\mathrm{a}=$ coeficiente angular; $\mathrm{b}=$ coeficiente linear

Os coeficientes lineares, angulares e de correlação correspondentes estão apresentados na Tabela VIII. As relações lineares referentes a consistência, firmeza e energia para penetração do cone apresentaram coeficien-

TABELA IV - Consistência do creme vegetal com fitosteróis, de sua gordura e dos ésteres de fitosteróis

\begin{tabular}{cccc}
\hline Temperatura $\left(\mathbf{~}^{\mathbf{C}} \mathbf{C}\right)$ & \multicolumn{3}{c}{ Consistência $\pm \mathbf{D P} \mathbf{( g f / \mathbf { c m } ^ { 2 } )}$} \\
\cline { 2 - 4 } & Creme vegetal & Gordura do creme vegetal & Ésteres de fitosteróis \\
\hline 5 & $1034,8 \pm 23,2$ & $568,7 \pm 31,1$ & $405,2 \pm 121,7$ \\
10 & $930,8 \pm 8,7$ & $452,9 \pm 44,1$ & 0 \\
15 & $826,7 \pm 3,3$ & $349,9 \pm 22,5$ & - \\
20 & $707,5 \pm 1,6$ & 0 & - \\
25 & $455,2 \pm 15,7$ & - & - \\
30 & $281,0 \pm 6,5$ & - & - \\
\hline
\end{tabular}

TABELA V - Firmeza do creme vegetal com fitosteróis, de sua gordura e dos ésteres de fitosteróis

\begin{tabular}{cccc}
\hline Temperatura $\left({ }^{\mathbf{0}} \mathbf{C}\right)$ & \multicolumn{3}{c}{ Firmeza $\pm \mathbf{D P} \mathbf{( g f} / \mathbf{c m})$} \\
\cline { 2 - 4 } & Creme vegetal & Gordura do creme vegetal & Ésteres de fitosteróis \\
\hline 5 & $332,0 \pm 9,0$ & $173,7 \pm 11,9$ & $117,8 \pm 40,5$ \\
10 & $294,5 \pm 3,7$ & $135,8 \pm 14,9$ & 0 \\
15 & $263,5 \pm 3,5$ & $101,0 \pm 6,4$ & - \\
20 & $220,1 \pm 2,5$ & 0 & - \\
25 & $136,1 \pm 4,2$ & - & - \\
30 & $76,4 \pm 3,7$ & - & - \\
\hline
\end{tabular}


TABELA VI - Energia necessária para penetração do cone no creme vegetal com fitosteróis, em sua gordura e nos ésteres de fitosteróis

\begin{tabular}{cccc}
\hline Temperatura $\left({ }^{\mathbf{0}} \mathbf{C}\right)$ & \multicolumn{2}{c}{ Energia necessária para penetração do cone \pm DP $($ gf.cm) } \\
\cline { 2 - 4 } & Creme vegetal & Gordura do creme vegetal & Ésteres de fitosteróis \\
\hline 5 & $152,7 \pm 3,3$ & $94,4 \pm 3,1$ & $66,7 \pm 16,6$ \\
10 & $139,4 \pm 0,8$ & $78,9 \pm 6,2$ & 0 \\
15 & $124,8 \pm 0,4$ & $62,6 \pm 3,8$ & - \\
20 & $111,0 \pm 0,7$ & 0 & - \\
25 & $76,1 \pm 3,0$ & - & - \\
30 & $50,6 \pm 1,0$ & - & - \\
\hline
\end{tabular}

TABELA VII - Adesividade do creme vegetal com fitosteróis, de sua gordura e dos ésteres de fitosteróis

\begin{tabular}{cccc}
\hline Temperatura $\left({ }^{\mathbf{0}} \mathbf{C}\right)$ & \multicolumn{3}{c}{ Adesividade \pm DP (gf.cm) } \\
\cline { 2 - 4 } & Creme vegetal & Gordura do creme vegetal & Ésteres de fitosteróis \\
\hline 5 & $50,4 \pm 7,0$ & $17,1 \pm 1,2$ & $59,4 \pm 6,9$ \\
10 & $44,2 \pm 3,2$ & $18,5 \pm 1,9$ & 0 \\
15 & $44,6 \pm 1,7$ & $16,9 \pm 1,2$ & - \\
20 & $41,3 \pm 1,8$ & 0 & - \\
25 & $31,3 \pm 1,5$ & - & - \\
30 & $22,7 \pm 0,5$ & - & - \\
\hline
\end{tabular}

tes de correlação $>0,9988$, sendo as correlações significativas a $\mathrm{p}<0,05$. Apenas a adesividade não apresentou correlação entre o creme vegetal e sua base gordurosa.

TABELA VIII - Coeficientes lineares, angulares e de correlação das relações lineares entre as propriedades de textura do creme vegetal com fitosteróis e sua base gordurosa

\begin{tabular}{lccc}
\hline Propriedade de textura & $\mathbf{a}$ & $\mathbf{b}$ & $\mathbf{R}^{\mathbf{2}}$ \\
\hline Consistência & 0,95 & 496,46 & 0,9988 \\
Firmeza & 0,94 & 167,64 & 0,9991 \\
Energia de penetração & 0,88 & 69,97 & 0,9998 \\
Adesividade & $-1,79$ & 77,72 & 0,2021 \\
\hline
\end{tabular}

Também foi estabelecida uma correlação entre as propriedades de firmeza, energia para penetração do cone e adesividade com a consistência das amostras de creme vegetal com fitosteróis, cujos coeficientes lineares, angulares e de correlação constam da Tabela IX. As relações lineares referentes a firmeza e energia apresentaram coeficientes de determinação $>0,9946$, sendo significativas a $\mathrm{p}<0,05$. A adesividade também não apresentou correlação significativa para esta relação.
TABELA IX - Coeficientes lineares e angulares e $\mathrm{R}^{2}$ das relações lineares entre a consistência e as outras propriedades de textura do creme vegetal com fitosteróis

\begin{tabular}{lccc}
\hline Propriedade & $\mathbf{a}$ & $\mathbf{b}$ & $\mathbf{R}^{\mathbf{2}}$ \\
\hline Firmeza & 3,10 & 22,27 & 0,9980 \\
Energia de penetração & 6,76 & $-31,65$ & 0,9946 \\
Adesividade & 19,83 & $-74,83$ & 0,9347 \\
\hline
\end{tabular}

As gorduras podem ser classificadas quanto à sua espalhabilidade em função de seu "yield value", segundo Haighton (1959). Uma gordura pode ser considerada espalhável na faixa entre 100 e $1000 \mathrm{gf} / \mathrm{cm}^{2}$, mas os valores ideais de "yield value" estão compreendidos na faixa de 200 a $800 \mathrm{gf} / \mathrm{cm}^{2}$. Com base nestes valores, o creme vegetal com fitosteróis apresentou espalhabilidade satisfatória em praticamente todas as temperaturas em que foi analisado. Apenas a $5{ }^{\circ} \mathrm{C}$, a consistência se apresentou ligeiramente maior que $1.000 \mathrm{gf} / \mathrm{cm}^{2}$, porém, a temperatura de refrigeração doméstica geralmente está situada entre 5 e $10^{\circ} \mathrm{C}$.

A Figura 1 apresenta a comparação entre as propriedades de textura de diferentes margarinas comerciais 
duras e cremosas de 10 a $35^{\circ} \mathrm{C}$ (Gioielli, 1996b), com o creme vegetal enriquecido com fitosteróis.

O creme vegetal com fitosteróis apresentou consistência, firmeza, energia para penetração do cone e adesividade maiores do que as margarinas cremosas em todas as temperaturas analisadas. $\mathrm{A} 10^{\circ} \mathrm{C}$, o creme vegetal com fitosteróis apresentou consistência de $930,8 \mathrm{gf} / \mathrm{cm}^{2}$, enquanto a média entre as consistências das margarinas cremosas estava em $766,8 \mathrm{gf} / \mathrm{cm}^{2}$, o que significa espalhabilidade satisfatória à temperatura de refrigeração para ambos. Já a $25^{\circ} \mathrm{C}$, temperatura ambiente, o creme vegetal apresentou consistência de $455,2 \mathrm{gf} / \mathrm{cm}^{2}$ e as margarinas cremosas, $125,3 \mathrm{gf} / \mathrm{cm}^{2}$, valor de consistência para as margarinas cremosas, que significa um produto macio demais, não mais espalhável. O creme vegetal com fitosteróis, portanto, conseguiu manter sua consistência em faixa de temperatura mais ampla que as margarinas cremosas, que não apresentaram espalhabilidade satisfatória à temperatura ambiente.

As margarinas comerciais duras, por outro lado, apresentaram consistência sempre maior que o creme vegetal com fitosteróis, e espalhabilidade satisfatória apenas a partir de $20^{\circ} \mathrm{C}$. À temperatura de refrigeração $\left(10^{\circ} \mathrm{C}\right)$ apresentaram consistência de $1819,4 \mathrm{gf} / \mathrm{cm}^{2}$ e a $30^{\circ} \mathrm{C}$ já não apresentavam espalhabilidade. Mudanças bruscas de consistência em função da temperatura não são consideradas como comportamento adequado para margarinas e spreads em geral, pois estes devem manter sua consistência de modo que sejam espalháveis ao menos entre as temperaturas de refrigeração doméstica e ambiente. Segundo Andersen e Williams (1965), uma margarina ideal seria aquela cuja fase gordurosa não apresentasse varia-
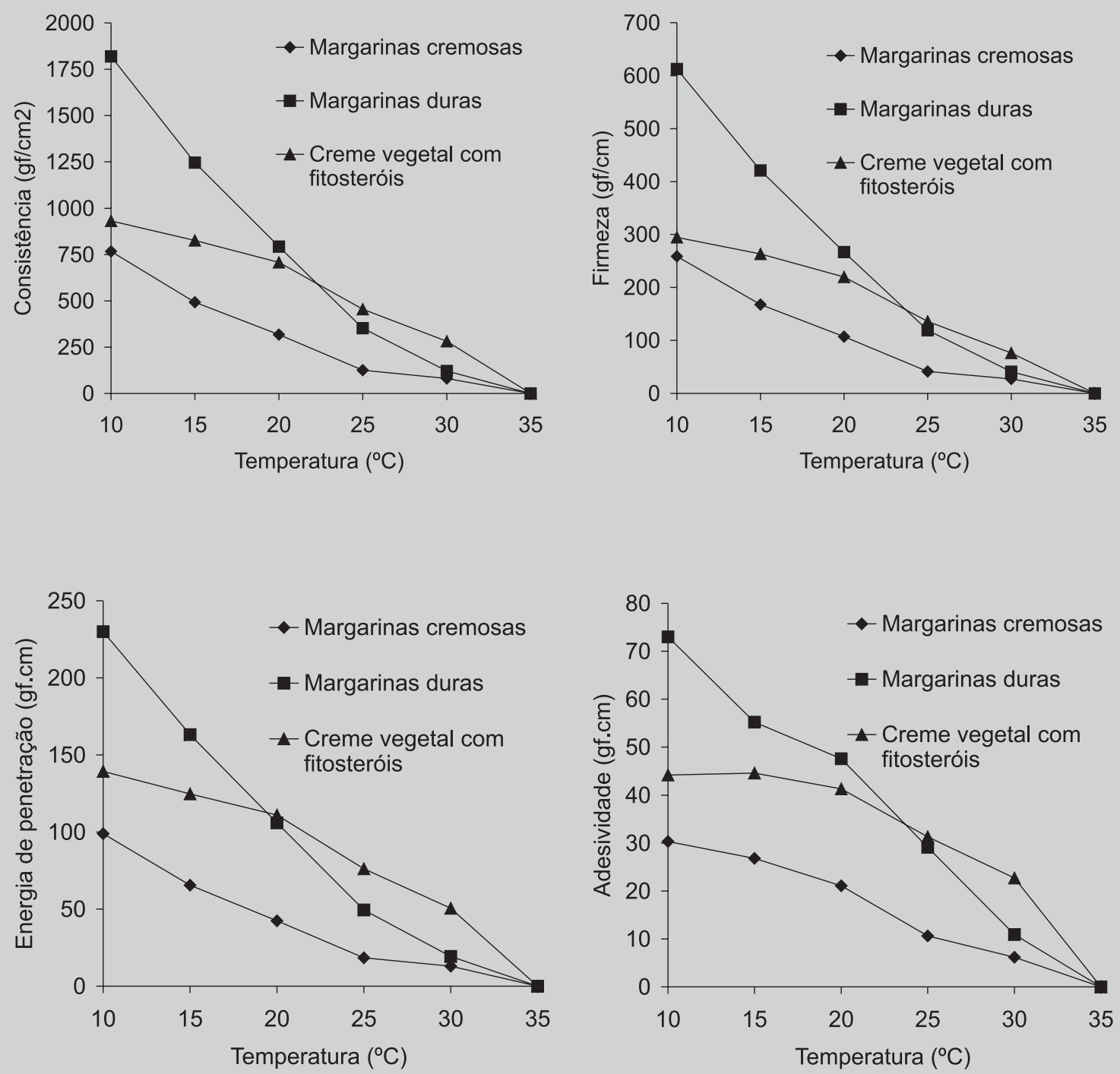

FIGURA 5 - Propriedades de textura de margarinas cremosas, margarinas duras e creme vegetal com fitosteróis. 
ções em seu conteúdo de gordura sólida até aproximadamente $35-38{ }^{\circ} \mathrm{C}$, quando então fundiria imediatamente.

As condições de processamento de margarinas e cremes vegetais são tão importantes na determinação de suas propriedades físicas quanto a composição de sua fase gordurosa. As principais propriedades, como consistência e plasticidade, dependem, basicamente, de fatores como método de resfriamento, tratamento térmico após o resfriamento (temperagem), tempo e grau de trabalho mecânico, tamanho e forma dos cristais (estrutura cristalina) e estado da emulsão (Gioielli, 1996b).

As gorduras das margarinas comerciais, tanto as duras quanto as cremosas, apresentaram consistência maior que a da gordura do creme vegetal com fitosteróis. A $10{ }^{\circ} \mathrm{C}$, a gordura das margarinas duras apresentou consistência igual a $2379,7 \mathrm{gf} / \mathrm{cm}^{2}$, a das margarinas cremosas $1108,1 \mathrm{gf} / \mathrm{cm}^{2}$ e a do creme vegetal com fitosteróis apenas $452,8 \mathrm{gf} / \mathrm{cm}^{2}$. Esta última apresentou consistência apenas até $15^{\circ} \mathrm{C}$, enquanto as outras resistiram até $30^{\circ} \mathrm{C}$, comportamento semelhante às margarinas que as contêm. Isto porque, de acordo com informações contidas no rótulo do creme vegetal com fitosteróis, este não contém gorduras hidrogenadas em sua formulação, ao contrário das outras margarinas. Foram utilizadas apenas gorduras submetidas à interesterificação, processo de modificação de óleos e gorduras, que mantém a composição em ácidos graxos do material inicial, mas modifica sua composição em triacilgliceróis e, conseqüentemente, altera suas propriedades físicas, porém com intensidade menor que a hidrogenação (Hui, 1996)

O fato de o creme vegetal conseguir manter sua consistência em larga faixa de temperatura, apesar de a gordura utilizada na sua fabricação ser pouco resistente ao calor, provavelmente é devido às suas condições de processamento.

Uma emulsão geralmente é definida como uma dispersão de gotículas de um líquido em outro, sendo que os dois são imiscíveis. Em alimentos, as emulsões têm um significado mais amplo, visto que em vários sistemas, sólidos e/ou gases também podem estar presentes (Rousseau, 2000). Margarinas e cremes vegetais são emulsões do tipo água em óleo (A/O), em que os glóbulos de água são conservados separados por cristais de gordura (Segura et al., 1995). A temperatura de emulsificação de uma margarina pode influenciar na estabilidade de sua consistência, como observaram Miskandar et al. (2002). Os pesquisadores verificaram que margarinas à base de óleos de palma refinado tiveram sua consistência diminuída conforme se aumentava a temperatura de emulsificação de $40{ }^{\circ} \mathrm{C}$ para $50^{\circ} \mathrm{C}$.

Além da emulsificação, a temperatura de cristalização e/ou o grau de resfriamento que levará à cristalização de margarina ou creme vegetal também influenciam fortemente em suas propriedades de textura. As gorduras utilizadas para a fabricação de margarinas são gorduras plásticas, que consistem em rede cristalina em matriz oleosa contínua (Rousseau et al., 1996). Durante o resfriamento, devido a interações atrativas entre os cristais, estes tendem a formar aglomerados, que juntos formam a rede cristalina que retém a matriz oleosa. Os cristais muito grandes são normalmente compostos por vários cristais pequenos unidos por ligações fracas. Portanto, geralmente o resfriamento lento resulta em cristais grandes e redes cristalinas mais firmes, enquanto que o resfriamento rápido produz cristais menores e estruturas cristalinas mais frágeis (Hui, 1996). Da mesma maneira, a agitação leva à formação de cristais microscopicamente pequenos, como os encontrados em margarinas (Timms, 1995). Assim, quanto mais rápido o resfriamento e maior o grau de agitação, menos resistente será a estrutura cristalina de uma gordura, e, conseqüentemente, menores serão sua consistência e espalhabilidade.

Portanto, existe a possibilidade de que o fabricante do creme vegetal com fitosteróis tenha modificado a tecnologia de fabricação de margarinas, trabalhando os processos de emulsificação e cristalização, pois a partir de uma base gordurosa com pouca consistência foi desenvolvido um produto macio e que, ao mesmo tempo, consegue manter sua plasticidade em larga faixa de temperatura. Outra possibilidade é a influência dos ésteres de fitosteróis e de sua interação com a base gordurosa na textura da margarina que os contém. O processo de emulsificação dos ésteres de fitosteróis e a estrutura desta emulsão também não são conhecidos e podem interferir na textura da margarina.

O comportamento de cristalização de lipídios tem implicações muito importantes, principalmente no processamento industrial de produtos cujas características dependem, em grande parte, de cristais de gorduras, como chocolates, manteigas, margarinas e shortenings (Sato, 2001).

A Figura 6 apresenta as imagens da estrutura cristalina da gordura do creme vegetal com fitosteróis (GCVF) e dos ésteres de fitosteróis (EF). A GCVF a 10 e $15{ }^{\circ} \mathrm{C}$ apresentou pequenos esferulitos, de cerca de $1 \mu \mathrm{m}$, e em grandes quantidades, propriedade característica de resfriamentos rápidos, realizados a baixas temperaturas (Marangoni, 2002). Além dos cristais isolados, a amostra apresentou também aglomerados de cristais de até $7 \mu \mathrm{m}$, sendo que o comportamento de cristalização foi muito semelhante em ambas as temperaturas. A $20^{\circ} \mathrm{C}$, porém, formaram-se cristais maiores, de até $5 \mu \mathrm{m}$, e em menor quantidade, tendência observada quando se aumenta a 
temperatura de cristalização. Os aglomerados também são menos freqüentes. Assim, a $25^{\circ} \mathrm{C}$ foram encontrados cristais de até $8 \mu \mathrm{m}$ e em quantidade ainda menor. Alguns cristais maiores foram encontrados apenas em algumas regiões da lâmina (Figura 6), medindo de 12 a $18 \mu \mathrm{m}$. É possível que sejam produto da cristalização de triacilgliceróis mais saturados, de alto ponto de fusão, presentes em pequena quantidade neste creme vegetal. Estes cristais são geralmente mais estáveis, mais densos e mais organizados (Marangoni, 2002). A $30{ }^{\circ} \mathrm{C}$, foram encontrados cristais em quantidades muito pequenas e de tamanho muito variável, chegando a $30 \mu \mathrm{m}$. A $35^{\circ} \mathrm{C}$, foram observados alguns poucos núcleos de cristais, apenas nas regiões periféricas das lâminas.

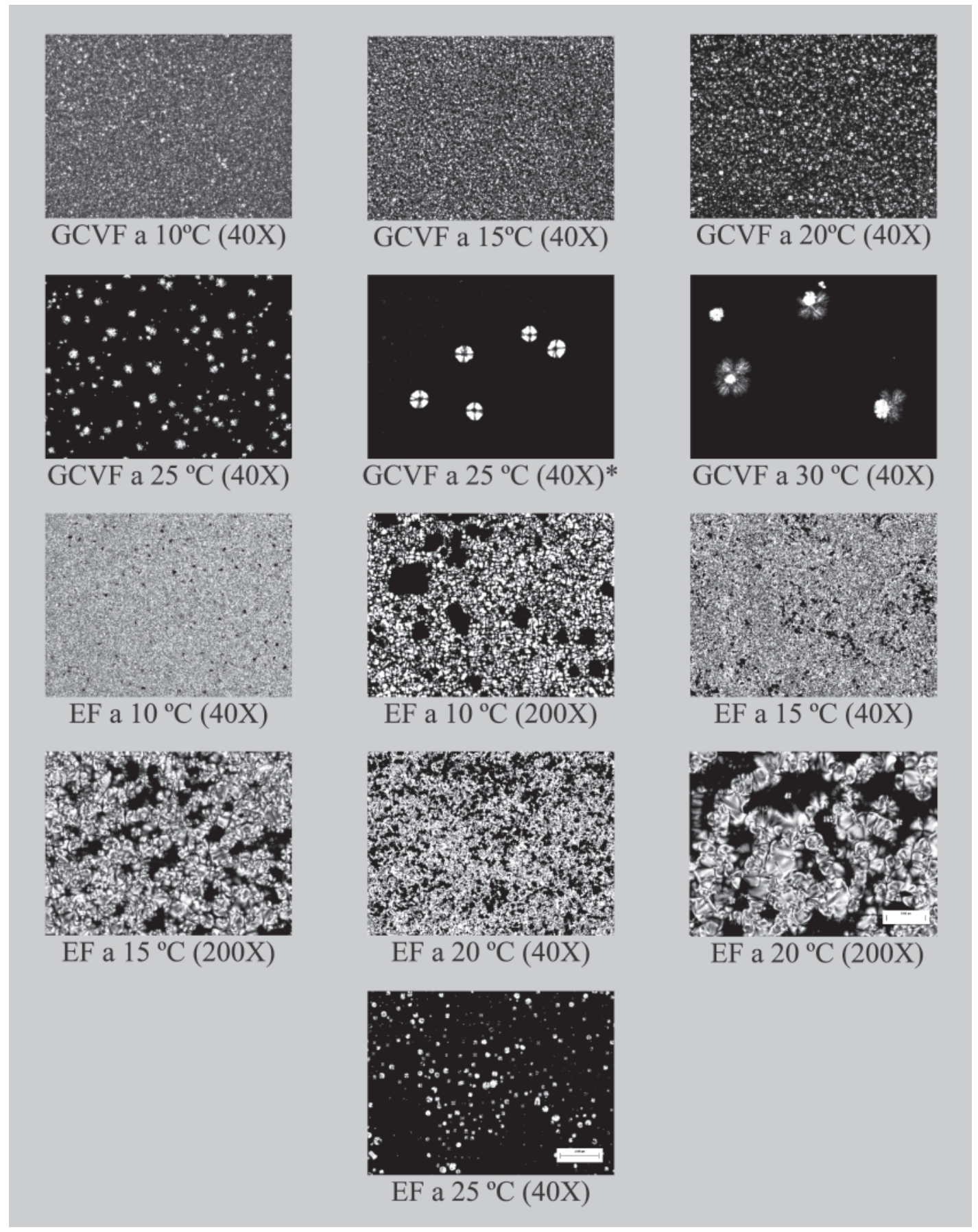

FIGURA 6 - Imagens da gordura do creme vegetal com fitosteróis e dos ésteres de fitosteróis obtidas por microscopia sob luz polarizada utilizando aumento de 40X (a barra representa $250 \mu \mathrm{m}$ ) e 200X (a barra representa $100 \mu \mathrm{m}$ ). *Cristais maiores medindo de 12 a $18 \mu \mathrm{m}$. Simbologia: $\mathrm{EF}=$ ésteres de fitosteróis; GCVF = gordura do creme vegetal com fitosteróis 
Os ésteres de fitosteróis são classificados como lipídio, porém apresentam características de cristalização muito diferentes dos óleos e gorduras comestíveis. Estes são constituídos principalmente de triacilgliceróis e pequenas quantidades de componentes menores (Gunstone, Harwood, Padley, 1986). Já os ésteres de fitosteróis constituem mistura complexa de vários tipos de esteróis e ácidos graxos diferentes, a maioria esterificada entre si (Leeson, Floter, 2002). Esta estrutura complexa dificulta a cristalização, pois moléculas assimétricas têm maior dificuldade para o empacotamento no estado cristalino (Narine, Marangoni, 1999). À temperatura de $25^{\circ} \mathrm{C}$, os ésteres de fitosteróis apresentaram cristais circulares ou esféricos, os chamados esferulitos, como as gorduras formadas principalmente por triacilgliceróis. Em todas as outras temperaturas analisadas, os ésteres de fitosteróis formaram uma rede cristalina sólida e densa, com cristais disformes e de tamanhos variados. Esta rede, porém, não parece ser formada de aglomerados de cristais, mas sim por estrutura maior, formada de uma só vez, sem migração (movimentação) de partículas menores para formar estrutura maior. De 10 a $20^{\circ} \mathrm{C}$, este se comporta como gordura plástica, com a fração líquida do lipídio distribuída entre a rede cristalina. A $30^{\circ} \mathrm{C}$, não houve formação de cristais.

A dimensão fractal de lipídios quantifica o nível da estruturação molecular de uma rede cristalina. Esta propriedade foi determinada para a gordura do creme vegetal com fitosteróis e está apresentada na Tabela X.

TABELA X - Dimensão fractal da gordura do creme vegetal com fitosteróis

\begin{tabular}{cc}
\hline Temperatura $\left({ }^{\mathbf{}} \mathbf{C}\right)$ & Dimensão fractal \pm DP \\
\hline 10 & $1,82 \pm 0,04$ \\
15 & $1,78 \pm 0,03$ \\
20 & $1,82 \pm 0,02$ \\
25 & $1,50 \pm 0,13$ \\
\hline
\end{tabular}

A gordura do creme vegetal apresentou valores muito próximos de dimensão fractal às temperaturas de 10 a $20^{\circ} \mathrm{C}$ e queda para 1,50 de 20 para $25^{\circ} \mathrm{C}$. A $30^{\circ} \mathrm{C}$, a gordura possui poucos cristais, não apresentando mais sinais de formação de rede cristalina, e sua estrutura não é mais descrita pela teoria fractal. Todas as propriedades de textura do creme vegetal também apresentaram queda acentuada entre 20 e $25^{\circ} \mathrm{C}$, segundo a Figura 5, provavelmente devido à fusão de grande parte dos triacilgliceróis nesta faixa de temperatura, como pode ser observado na Figura 6.

\section{CONCLUSÕES}

Além da presença dos fitosteróis, um creme vegetal enriquecido com esta substância representa fonte rica em ácidos graxos insaturados e pobre em ácidos graxos trans, devido à preocupação do fabricante em substituir as gorduras parcialmente hidrogenadas, geralmente presentes na composição de margarinas, por óleos vegetais interesterificados. Dessa maneira, seu consumo pode contribuir para a manutenção de uma dieta saudável. Embora seja um pouco mais duro do que as margarinas cremosas comercialmente disponíveis, o creme vegetal com fitosteróis apresenta plasticidade satisfatória na faixa de temperatura entre a de refrigeração doméstica e a ambiente e maior resistência à temperatura do que as margarinas cremosas. A estrutura cristalina e, conseqüentemente, a dimensão fractal do produto sofreram mudanças mais acentuadas entre 20 e $25^{\circ} \mathrm{C}$, assim como as propriedades de textura, provavelmente devido à fusão de grande parte dos triacilgliceróis nesta faixa de temperatura. Em geral, os ésteres de fitosteróis apresentaram comportamento de fusão e cristalização bem diferentes dos óleos e gorduras comestíveis.

\section{AGRADECIMENTOS}

À Fundação de Amparo à Pesquisa do Estado de São Paulo-FAPESP, ao Conselho Nacional de Desenvolvimento Científico e Tecnológico-CNPq e à Coordenação de Aperfeiçoamento de Pessoal de Nível Superior-CAPES, pelo auxílio financeiro e pelas bolsas concedidas aos autores. À Tovani Benzaquen Representações Ltda., pela doação dos ésteres de fitosteróis. Ao Prof. Alejandro Marangoni, da Universidade de Guelph, pela doação do software Benoit 1.3, utilizado para o cálculo da dimensão fractal das amostras. A Ken Baker, pelas técnicas de microscopia e obtenção de imagens.

\section{ABSTRACT}

\section{Physico-chemical characterization of a phytosterol ester enriched margarine}

Recently, sterol and stanol esters have been added to special margarines, which are commercially available as functional foods with the ability to reduce both total and LDL cholesterol levels. As part of a healthy diet, this type of product has been scientifically proven to lower blood LDL cholesterol by around 10-15\%, which implies a dramatic lowering in coronary heart disease risk by 25\%. Current literature on this field provides a great amount of information on the effects 
of phytosterols/phytostanols in cholesterol lowering and attempts to explain their metabolism in human body, but researches on their physical and chemical properties and their application in food products are limited in the food technology area. The objective of this study is to characterize a phytosterol ester enriched margarine and to compare their physical behavior to common margarines commercially available. Fatty acid and sterol compositions were determined by gasliquid cromatography and a constant speed texture analyser was used to evaluate the texture profiles of the samples. The phytosterol ester-enriched margarine contains $49.3 \%$ of moisture, $49.6 \%$ of lipids and $1.1 \%$ of solids. $\beta$-Sitosterol is the most abundant sterol, totalizing $36.1 \%$. Linoleic acid (C18:2 n-6) is the fatty acid that is present in the greatest amount and corresponds to $45.3 \%$ of total fatty acid composition. In general, texture properties of the fat base and its respective spread presented a significant linear correlation. Although harder than common margarines commercially available, margarine with phytosterol esters presents good spread ability in the range of temperature between room and refrigeration and is more resistant to higher temperatures than common margarines. In general, the phytosterol esters presented melting and crystallization behavior quite different from other edible fats and oils.

UNITERMS: Margarine. Phytosterol esters. Crystallization

\section{REFERÊNCIAS BIBLIOGRÁFICAS}

AMERICAN OIL CHEMISTS' SOCIETY. Official methods and recommended practices of the AOCS. 4. ed. Champaign, 1990.

ANDERSEN, A.J.C.; WILLIAMS, P.N. Margarine. 2. ed. Oxford: Pergamon Press, 1965. p.161-322.

BLOCK, J.M.; BARRERA-ARELLANO, D. Produtos hidrogenados no Brasil: isômeros trans, características físico-químicas e composição em ácidos graxos. Arch. Latinoam. Nutr., Caracas, v.44, n.4, p.281-285, 1994.

BRASIL, Leis, decretos, etc. Portaria n.193 de 09 mar. 1999 da Agência Nacional de Vigilância Sanitária. Aprova o regulamento técnico referente a creme vegetal constante do anexo desta portaria. Disponível em: $<$ http:// www.anvisa.gov.br/legis/portarias/193_99.htm > Acesso em: 14 jan. 2004.
BRASIL, Leis, decretos, etc. Portaria n.372 de 04 set. 1997 do Ministério da Agricultura, DIPOA (Divisão de Inspeção de Produtos de Origem Animal). Disponível em: $<$ http://www.agricultura.gov.br/sda/dipoa/ regmargarina.htm>. Acesso em: 30 set. 2002.

BRASIL, Leis, decretos, etc. Resolução n.482 de 23 de setembro de 1999. Disponível em: <http:// www.anvisa.gov.br/legis/resol/482_99.htm $>$.Acesso em: 14 jan. 2004.

D'AGOSTINI, D.; FERRAZ, R.C.; GIOIELLI, L.A. Consistência de misturas binárias e ternárias de gorduras de palma, palmiste e triacilgliceróis de cadeia média. Rev. Bras. Ciênc. Farm., São Paulo, v. 36, n. 1, p. 147-155, 2000.

DANTAS, V. Aumenta disputa no segmento de margarinas. Publicado em 19 jun. 2000. Disponível em $<$ http:// www.estado.estadao.com.br/editorias/2000/06/19/ eco343.html>. Acesso em: 05 mai. 2003.

DEMAN, J.M. Consistency of fats: a review. J. Am. Oil Chem. Soc., Champaign, v.60, n.1, p.82-87, 1983.

DILLARD, C.J.; GERMAN, B. Review - Phytochemicals: nutraceuticals and human health. J. Sci. Food Agric., London, v.80, n.12, p.1744-1756, 2000.

GIOIELLI, L.A. Lipídios estruturados. In: CURI, R.; POMPÉIA, C.; MIYASAKA, C.K.; PROCÓPIO, J., eds. Entendendo a gordura: Os ácidos graxos. São Paulo: Manole, 2002. p.457-465.

GIOIELLI, L.A. Margarinas e cremes vegetais: composição e tecnologia. Óleos e Grãos, São Caetano do Sul, v. 7, n. 33, p. 21-27, 1996a.

GIOIELLI, L.A. Misturas binárias e ternárias de gorduras hidrogenadas na formulação de margarinas. 1996b. 253 p. [Tese de Livre-Docência. Faculdade de Ciências Farmacêuticas da USP].

GIOIELLI, L.A.; SIMÕES, I.S.; RODRIGUES, J.N. Crystal morphology and interactions of binary and ternary mixtures of hydrogenated fats. J. Food Eng., Oxford, v.57, n.4, p.347-355, 2003.

GUNSTONE, F.D.; HARWOOD, J.L.; PADLEY, F.B. The lipid handbook. Londres: Chapman and Hall, 1986. 896p. 
HAIGHTON, A. J. The measurement of the hardness of margarine and fats with cone penetrometers. J. Am. Oil Chem. Soc., Champaign, v. 36, n. 8, p. 345-348, 1959.

HARTMAN, L.; LAGO, R. C. A. Rapid preparation of fatty acid methyl esters from lipids. Lab. Pract., London, v. 22, p. 475-476, 494, 1973.

HORNSTRA, G. Lipids in functional foods in relation to cardiovascular disease. Fett/Lipid, Berlin, v.101, n.12, p.456-466, 1999.

HUI, Y. H., ed. - Bailey's industrial oil and fat products. 5. ed. New York: Wiley, 1996. v.3, p.65-114.

KOLETZCO, B.; DECSI, T. Metabolic aspects of trans fatty acids. Clin. Nutr. Edinburgh, v.16, n.5, p.229-237, 1997.

LACKEY, J. Agricultural biotechnology: Rapeseed. Disponível em: $<$ http://www.aphis.usda.gov/ppq/biotech/ rapeseed.html>. Acesso em: 05 mai. 2003.

LAJOLO, F. Alimentos funcionais: Legislação brasileira. In: SEMINÁRIO INTERNACIONAL SOBRE ALIMENTOS FUNCIONAIS, 1, São Paulo, 1999. (CD-ROM).

LEESON, P.; FLOTER, E. Solidification behaviour of binary sitosteryl esters mixtures. Food Res. Int., Amsterdam, v.35, n.10, p.983-991, 2002.

LICHTENSTEIN, A.H.; AUSMAN, L.M.; JALBERT, S.M.; SCHAFER, E.J. Effects of different forms of dietary hydrogenated fats on serum lipoprotein cholesterol levels. New England J. Med., Waltham, v.340, n.25, p.1933-1940, 1999.

LICHTENSTEIN, A.H.; ERKKILA, A.T.; LAMARCHE, B.; SCHWAB, U.S.; JALBERT, S.M.; AUSMAN, L.M. Influence of hydrogenated fat and butter on CVD risk factors: remnant-like particles, glucose and insulin, blood pressure and C-reactive protein. Atherosclerosis, Clare, v.171, n.1, p.97-107, 2003.

LICHTENSTEIN, A.H.; JAUHIANEN, M.; MCGLADDERY, S.; AUSMAN, L.M.; JALBERT, S.M.; VILELLA-BACH, M.; EHNHOLM, C.; FROHLICH, J.; SCHAEFER, E.J. Impact of hydrogenated fat on high density lipoprotein subfractions and metabolism. J. Lipid Res., Bethesda, v.42, n.4, p.597604, 2001.
MARANGONI, A.G. Special issue of FRI - Crystallization, structure and functionality of fats. Food Res. Int., Amsterdam, v.35, n.10, p.907-908, 2002.

MISKANDAR, M.S.; MAN, Y.B.C.; YUSOFF, M.S.A.; RAHMAN, R.A. Effect of emulsion temperature on physical properties of palm oil-based margarine. $J . A m$. Oil Chem. Soc., Champaign, v.79, n.12, p.1163, 1168, 2002.

MULLER, H.; KIRKHUS, B.; PEDERSEN, J.I. Serum cholesterol predictive equations with special emphasis on trans and saturated fatty acids. An analysis from designed controlled studies. Lipids, Champaign, v.36, n.8, p.783791, 2001.

NAEEMI, E.D.; AHMAD, N.; ALSHARRAH, T.K.; BEHBAHANI, M. Rapid and simple method for determination of cholesterol in processed food. J. AOAC Int., Gaithersburg, v.78, n.6, p.1522-1525, 1995.

NARINE, S.S.; MARANGONI, A.G. The difference between cocoa butter and Salatrim lies in the microstructure of the fat crystal network. J. Am. Oil Chem. Soc., v.76, n. 1, p.7-13, 1999.

NAWAR, W.W. Lipids. In: FENNEMA, O.R., ed. Food chemistry. 2.ed. New York: Marcel Dekker, 1985. p.139244.

NESTEL, P.; CEHUN, M.; POMEROY, S.; ABBEY, M.; WELDON, G. Cholesterol-lowering effects of plant sterol esters and non-esterified stanols in margarine, butter and low-fat foods. Eur. J. Clin. Nutr., Basingstoke, v.55, n.12, p.1084-1090, 2001.

NTANIOS, F. Plant sterol-ester-enriched spreads as an example of a new funtional food. Eur. J. Lipid Sci. Tech., Berlin, v. 103, n. 2, p. 102-106, 2001.

OLIVEIRA, M.A.L.; SOTERO SOLIS, V.E.; GIOIELLI, L.A.; POLAKIEWICZ, B.; TAVARES, M.F.M. Method development for the analysis of trans-fatty acids in hydrogenated oils by capillary electrophoresis. Electrophoresis, Berlin, v. 24, n. 10, p. 1641-1647, 2003.

PIIRONEN, V.; LINDSAY, D.G.; MIETTINEN, T.A.; TOIVO, J.; LAMPI, A.M. Review - Plant sterols: biosynthesis, biological function and their importance to human nutrition. J. Sci. Food Agric., London, v.80, n.7, p.939-966, 2000. 
PREGNOLATTO, W. Normas analíticas do Instituto Adolfo Lutz: métodos químicos e físicos para análise de alimentos, 3.ed. São Paulo:Instituto Adolfo Lutz, 1985. p.245-266.

ROBERFROID, M.B. What is beneficial for health? The concept of functional food. Food Chem. Toxicol., Oxford, v.37, n.9-10, p.1039-1041, 1999.

RODRIGUES, J.N.; GIOIELLI, L.A.; ANTON, C. Propriedades físicas de lipídios estruturados obtidos de misturas de gordura do leite e óleo de milho. Ciênc. Tecnol. Aliment., Campinas, v.23, n.2, p.226-233, 2003.

ROUSSEAU, D. Fat crystals and emulsion stability - a review. Food Res. Int., Amsterdam, v.33, n.1, p.3-14, 2000 .

ROUSSEAU, D.; FORESTIERE, K.; HILL, A.R.; MARANGONI, A.G. Restructuring butterfat through blending and chemical interesterification. 1. Melting behavior and triacylglycerol modifications. J. Am. Oil Chem. Soc., Champaign, v.73, n.8, p.963-972, 1996.

ROUSSEAU, D.; HILL, A.R.; MARANGONI, A.G. Restructuring butterfat through blending and chemical interesterification. 2. Microstructure and polymorphism. J. Am. Oil Chem. Soc., Champaign, v.73, n.8, p.973-981, 1996 a.

ROUSSEAU, D.; HILL, A.R.; MARANGONI, A.G. Restructuring butterfat through blending and chemical interesterification. 3. Rheology. J. Am. Oil Chem. Soc., Champaign, v.73, n.8, p.983-989, 1996 b.

ROUSSEAU, D.; MARANGONI, A. G. The effects of interesterification on physical and sensory attributes of butterfat and butterfat-canola oil spreads. Food Res. Int., Amsterdam, v. 31, n. 5, p. 381-388, 1999.

SATO, K. Crystallization behaviour of fats and lipids - a review. Chem. Eng. Sci., City, v. 56, n. 7, p. 2255-2265, 2001.

SEGURA, J.A.; HERRERA, M.L.; ANON, M.C. Margarines: a rheological study. J. Am. Oil Chem. Soc., Champaign, v.72, n.3, p.375-378, 1995.
SIMÕES, I.S.; GIOIELLI, L.A. Crystal morphology of binary and ternary mixtures of hydrogenated fats and soybean oil. Braz. Arch. Biol. Technol., Curitiba, v.43, p.241-248, 2000.

SIMÕES, I.S.; GIOIELLI, L.A. Microscopia da cristalização parcial de misturas de gorduras hidrogenadas e óleo de soja. Rev. Bras. Ciênc. Farm., São Paulo, v.35, p.259266, 1999.

SOTERO-SOLIS, V.E.; GIOIELLI, L.A. Estrutura cristalina de las grasas hidrogenadas del aceite de castaña de Brasil (Bertholletia excelsa). Alimentaria, Madrid, v.38, n.322, p.131-137, 2001.

STAUFFER, C.E. Fats and oils. St. Paul: Eagan Press. 1996. p.131.

TIMMS, R.E. Crystallisation of fats. In: HAMILTON, R.J. Developments in oils and fats. London: Blackie Academic and Professional; Chapman \& Hall, 1995. p.204-223.

TURATTI, J.M. Efeito dos ácidos graxos $\omega$-3 e fitosteróis. Food Ingredients, São Paulo, v.3, n.15, p.54-58, 2001.

VOLPE, R.; NIITTYNEN, L.; KORPELA, R.; SIRTORI, C.; BUCCI, A.; FRAONE, N.; PAZZUCCONI, F. Effects of yoghurt enriched with plant sterols on serum lipids in patients with moderate hypercholesterolaemia. $\mathrm{Br}$. J. Nutr., Wallingford, v.86, n.2, p.233-239, 2001.

WEBER, N.; WEITKAMP, P.; MUKHERJEE, K.D. Cholesterol-lowering food additives: lipase-catalysed preparation of phytosterol and phytostanol esters. Food Res. Int., Amsterdam, v.35, n.2-3, p.177-181, 2002.

WILLIS, W.M.; LENCKI, R.W.; MARANGONI, A.G. Lipid modification strategies in the production of nutritionally functional fats and oils. Crit. Rev. Food Sci., Boca Raton, v.38, n.8, p.639-674, 1998.

WINNETT, R. “Alimentos estéticos", nova moda para 2003. Publicado em 23 jul. 2002. Disponível em: $<$ http:// www.estado.estadao.com.br/jornal/02/07/23/ news180.html>. Acesso em: 08 jan. 2003.

Recebido para publicação em 04 de fevereiro de 2004. Aceito para publicação em em 28 de outubro de 2004. 